\title{
POLISSACARÍDEOS DA BIODIVERSIDADE BRASILEIRA: UMA OPORTUNIDADE DE TRANSFORMAR CONHECIMENTO EM VALOR ECONÔMICO
}

\author{
Pablyana Leila R. da Cunha \\ Centro de Ciências Tecnológicas, Universidade de Fortaleza, CP 1258, 60811-905 Fortaleza - CE, Brasil \\ Regina Célia M. de Paula e Judith P. A. Feitosa* \\ Departamento de Química Orgânica e Inorgânica, Centro de Ciências, Universidade Federal do Ceará, CP 6021, 60455-760 Fortaleza - CE, \\ Brasil
}

Recebido em 21/1/09; aceito em 3/3/09; publicado na web em 17/3/09

\begin{abstract}
POLYSACCHARIDES FROM BRAZILIAN BIODIVERSITY: AN OPPORTUNITY TO CHANGE KNOWLEDGE INTO ECONOMIC VALUE. A brief comment about general characteristics of polysaccharide was presented. Brazilian trade of polysaccharides was obtained from the "Ministério de Desenvolvimento, Indústria e Comércio Exterior" - Brazil. A list of these products was prepared and their price and amount analyzed in the period of 1998-2007. Some chemical properties and application of polysaccharides from our biodiversity was described. In this review they were classified by origin, in vegetal (exudate, seed, fruit, seaweed), animal and bacteria source. There is a trade deficit that can be reverted if part of the accumulated scientific knowledge was used to promote the national economic development in the field.
\end{abstract}

Keywords: polysaccharide; Brazilian biodiversity; economic development.

\section{INTRODUÇÃO}

Biodiversidade foi definida por Arnt, de uma forma bem criativa, como sendo: "o cofre de um patrimônio químico inexplorado de remédios, alimentos, fertilizantes, pesticidas, cosméticos, solventes, fermentos, têxteis, plásticos, celulose, óleos e energia, além de moléculas, enzimas e genes em número quase infinito."

A diversidade contida no cofre é inexata. Estima-se que a diversidade da fauna nacional seja de cerca de 2 milhões de espécies de animais, exceto insetos, representando $14 \%$ da biota mundial. Para conhecê-la estima-se que seriam necessários mais dez séculos de trabalho, se o ritmo atual de estudo fosse mantido. ${ }^{2}$ Com relação à flora, acredita-se que existam no país cerca de 55 mil espécies vegetais ( $22 \%$ do total mundial), ${ }^{3}$ muitas ainda desconhecidas.

O valor econômico da nossa diversidade biológica é de difícil mensuração. Uma estimativa é de que seja próximo de 4 trilhões de dólares. ${ }^{4}$ Apesar desse elevado "valor econômico", sabe-se que ela por si só não é garantia de crescimento econômico. Transformar biodiversidade em desenvolvimento, através do seu uso sustentado e de seus recursos derivados, é o grande desafio. A etapa inicial para vencer esse desafio é transformar conhecimento em valor econômico e em bem-estar da população, uma das maiores preocupações das sociedades atuais.

Diversos produtos utilizados pela sociedade têm como fonte a flora brasileira. Medicamentos, alimentos e seus aditivos, fibras, óleos naturais e essenciais, cosméticos, produtos químicos, biocombustível, são alguns bons exemplos. Inúmeras são as classes de compostos químicos que podem ser extraídos das nossas espécies vegetais. Uma delas é representada pelos polissacarídeos. Pretende-se discorrer sobre o estado atual do conhecimento científico dos polissacarídeos da biodiversidade brasileira, e pontuar o potencial e a necessidade de aplicação industrial.

\footnotetext{
*e-mail: judith@dqoi.ufc.br
}

\section{CARACTERÍSTICAS GERAIS DE POLISSACARÍDEOS}

Polissacarídeos são polímeros naturais, os quais podem ser constituídos de um único ou de diferentes tipos de monossacarídeos. Celulose, alginato e goma arábica são exemplos de homo-, co-, e hetero- polissacarídeos, respectivamente. Aqueles com aplicações industriais são extraídos de plantas - incluindo as algas, de animais e fungos ou são obtidos via fermentação microbiológica. Nas plantas superiores estes podem ser obtidos de exsudatos, sementes, frutos e tubérculos (Tabela 1).

\section{Polissacarídeos de plantas}

$\operatorname{Algas}^{5}$

Algas são fonte de vários tipos de polissacarídeos. As algas vermelhas e as pardas são aquelas a partir das quais são extraídos os polissacarídeos mais utilizados na indústria.

Das algas vermelhas são obtidas as agaranas e as carragenanas, cuja estrutura básica é composta de uma cadeia linear, formada por unidades de $\beta$-D-galactose ligadas $1 \rightarrow 3$ (unidade $A$ ) a $\alpha$-D/L-galactose ligados nas posições $1 \rightarrow 4$ (unidade $B$ ) arranjadas na forma de uma unidade de repetição $(\mathrm{AB})_{\mathrm{n}}$. As unidades $\alpha$-D-galactose no dissacarídeo podem ser biologicamente convertidas no derivado 3,6 anidro pela eliminação de grupos sulfato na posição 6. Nas agaranas, a unidade $B$ está presente como $\alpha$-L-galactose, que pode estar na forma de 3,6-anidro ou pode ser substituída na posição 6 por grupos sulfato. As carragenanas diferenciam-se das agaranas por possuírem a unidade $B$ na forma de $\alpha$-D-galactose. As carragenanas são encontradas nas espécies Soliera, Eucheuma, Maristiella e Callophucis, e as agaranas nas espécies Gracilaria, Gelidium e Pterocladias.

Os alginatos são extraídos de algas pardas de espécies como: Macrocystis, Ascophyllum, Laminaria, Ecklonia e Sargassum. Eles possuem uma estrutura linear de ácidos manurônico $(\mathrm{M})$ e gulurônico (G). A distribuição dos blocos de $\mathrm{M}$ e $\mathrm{G}$ na estrutura bem como a razão $M / G$ influenciam fortemente nas suas propriedades em solução. Longos blocos GG (6 a 10 unidades) fazem com que esse polissa- 
Tabela 1. Fontes usuais de alguns polissacarídeos

\begin{tabular}{lll}
\hline Origem & Polissacarídeo & Fonte \\
\hline Algas & Alginato & $\begin{array}{l}\text { algas pardas } \\
\text { algas vermelhas } \\
\text { algas vermelhas }\end{array}$ \\
\hline Exsudato de Plantas & Carragenanas & Acacia spp \\
& Goma Arábica & Astragalus spp \\
\hline Sementes & Tragacante & Cyamopis tetragonolobus \\
& Guar & Ceratonia siliqua \\
\hline Frutas & Alfarroba & T. indica \\
\hline Tubérculo, cereais & Tamarindo & maçãs e laranjas \\
\hline Animais & Pectinas & milho, trigo, batatas \\
& Amido & chicória, Jerusalem artichokes \\
& Inulina & humor vítreo de bovinos, cristas de galináceos \\
& Ácido Hialurônico & pulmão de bovinos e intestinos de porcinos \\
& Heparina & carapaças de crustáceos \\
Fungos & Quitina & carapaças de crustáceos \\
\hline Bactérias & Quitosana & P. ostreatus, Agaricus blazei \\
& Glucanas & Xanthomonas ssp \\
& Xantana & Leuconostoc spp \\
\hline & Dextrana & Sphingmonas elodea
\end{tabular}

carídeo seja rígido, forme géis mais fortes e tenha maior capacidade de formar complexo com íons divalentes.

\section{Polissacarídeos de sementes ${ }^{6,7}$}

Os polissacarídeos de sementes podem ser divididos em de reservas ou estruturais. Os de reservas são os mais utilizados industrialmente. Esses polissacarídeos incluem galactomananas, xiloglucanas, glucanas e mananas, mas as duas primeiras destacam-se em aplicações industrial.

A estrutura química genérica das xiloglucanas de reserva consiste de uma cadeia principal celulósica de unidades de D-glucose, as quais podem estar substituídas em O-6 por unidades $\alpha$-D-xilopiranose; essas últimas, por sua vez podem estar substituídas por unidades de $\beta$-D-galactopiranose.

Galactomananas são obtidas principalmente de endosperma de plantas. Sua estrutura consiste de uma cadeia principal de unidades de $\alpha$-D-manose, com substituição de unidades simples de $\alpha$-D-galactose na posição do C-6 da manose. As espécies de maior utilização industrial, principalmente em alimentos, são as extraídas de Cyamopis tetragonolobus (goma guar) e de Ceratonia siliqua (alfarroba). A proporção de manose $(\mathrm{M})$ e galactose $(\mathrm{G})$ nestes polissacarídeos é, respectivamente, $\sim 1,7: 1 \mathrm{e} \sim 3: 1$.

\section{Exsudatos de plantas ${ }^{8}$}

Polissacarídeos de exsudatos são produzidos como mecanismo de defesa das plantas contra o estresse causado por injúrias físicas ou ataque microbiano. Esses polissacarídeos são heteropolissacarídeos complexos, ramificados e polidispersos. Ácidos carboxílicos, como ácido glucurônico e galacturônico, estão sempre presentes. Estruturalmente, eles podem ser divididos em três grupos principais. $\mathrm{O}$ primeiro grupo é composto de uma cadeia principal de unidades de $\beta$-D-galactose ligada com cadeias laterais de $\beta$-D-galactose e ácido glucurônico. O segundo grupo possui uma cadeia principal de $\beta$-Dácido glucurônico ligado à D-manose, com ramificações de arabinose e ácido glucurônico. O terceiro grupo consiste de uma cadeia de $\alpha$-D-ácido galacturônico ligado à $\alpha$-L-ramnose com ramificações de ácido glucurônico e $\beta$-D-galactose. Goma arábica (Acacia sp),
Goma ghati (Anogeissus latifólia), tragacante (Astragalus sp) e caraia (Sterculia urens) são as gomas de exsudato comercialmente mais utilizadas.

\section{Polissacarídeos de frutas $^{9,10}$}

O principal polissacarídeo extraído da parede celular de frutas pertence à classe das pectinas. Elas são heteropolissacarídeos constituídos de uma cadeia principal linear de $\alpha$-D-ácido galacturônico e de seus derivados O-metilados. Na cadeia principal podem existir regiões onde a cadeia linear de ácido galacturônico é quebrada pela presença de resíduos de $\alpha$-L-ramnose. $\mathrm{O}$ ácido galacturônico geralmente está esterificado. O grau de esterificação e o número e a distribuição de resíduos de ramnose dependem da fonte da pectina e têm grande influência na solubilidade e na capacidade de formar gel. A região de ácido galacturônico tem no mínimo 72-100 resíduos, independentemente da origem da pectina. As ramificações com açúcares neutros estão presentes nas regiões ricas em resíduos de ramnose. Nessas ramificações encontram-se predominantemente arabinose, galactose e arabinogalactanas.

\section{Tubérculos e cereais ${ }^{11}$}

Amido é o polissacarídeo de reserva mais abundante nas plantas e mais utilizado como alimento. Ele é uma mistura de dois polissacarídeos: amilose e amilopectina. A amilose é um polissacarídeo com cadeia linear de D-glucose, enquanto a amilopectina é um polímero ramificado, também, de D-glucose. Trigo e milho são os cereais mais utilizados na obtenção do amido.

Inulina é uma frutana composta de $\beta$-D-frutose ligada com uma unidade de glucose no início da cadeia. Elas são muito abundantes na natureza e estão presentes tanto em plantas (tubérculos ou raízes) como em algumas bactérias. As plantas utilizadas na obtenção industrial são: chicória, Jerusalem artichoque e Dahlia.

\section{Polissacarídeos de animais superiores}

Ácido hialurônico e a heparina são extraídos de animais superiores. O primeiro é obtido do humor vítreo de bovinos ou das cristas 
de galináceos e o segundo do pulmão dos bovinos e intestinos dos porcinos. Em animais marinhos invertebrados, polissacarídeos são encontrados em carapaças de crustáceos, ouriços-do-mar e estrelas-do mar. O principal deles é a quitina ( $\beta$ - $N$-acetil-D-glucosamina), que por desacetilação produz a quitosana.

Heparina possui em sua estrutura $\alpha$-D-ácido Idurônico-, $\alpha-N$ acetil-D-glucosamina sulfatadas e ácido hialurônico. Condroitim sulfato e heparam sulfato são formados por unidades de $\beta$-D-ácido glucurônico e $\beta$-N-acetil-D-glucosamina sulfatadas ou não. Vários desses polissacarídeos apresentam atividades biológicas.

\section{Polissacarídeos de liquens ${ }^{12}$ e fungos ${ }^{13}$}

Os liquens produzem carboidratos de alta e baixa massa molar. Dentre os de elevada massa molar, destacam-se os polissacarídeos de manose (galactomananas e galactoglucomana) e de glucose (nigerana, isoliquenanas, acrocifananas, pululanas, pseudonigeranas, laminarana, pustulana e liquenanas).

As glucanas são os homopolissacarídeos mais frequentemente encontrados em cogumelos. São formadas por $\alpha$ ou $\beta$ glucose, podendo haver ramificações por unidades monossacarídicas não redutoras.

\section{Polissacarídeos produzidos por bactérias ${ }^{14}$}

Os micro-organismos possuem a habilidade de sintetizar e secretar polissacarídeos (exopolissacarídeos). Os principais exopolissacarídeos com aplicações industriais são: xantana, gelana, dextrana, alginato, ácido hialurônico e pululana. A estrutura desses polissacarídeos pode ser bastante variada. Dextrana e pululana, por exemplo, são homopolissacarídeos de glucose. A cadeia é linear na pululana e ramificada na dextrana. Gelana é um heteropolissacarídeo constituído de ácido glucurônico, glucose, ramnose com grupos acetato e glicerato na sua estrutura.

\section{APLICAÇÕES CLÁSSICAS E DE FRONTEIRAS DE POLISSACARÍDEOS}

Polissacarídeos possuem uma ampla gama de aplicações, especialmente nas áreas de alimentos, biomédicas, farmacêutica e de cosméticos. Na indústria alimentícia, ${ }^{5}$ eles são empregados em grandes quantidades. A grande maioria é utilizada como estabilizante e espessante. Os polissacarídeos de algas são empregados, também, como agentes geleificantes. Gomas de sementes e de exsudatos, além de carboximetilcelulose (CMC) e metilcelulose, são utilizadas como retentor de umidade. Goma arábica serve, também, para encapsular aromas na indústria alimentícia.

$\mathrm{Na}$ área biológica eles são aplicados em engenharia de tecidos, imobilização de enzimas, biossensores, como veículo de liberação de fármaco etc. Rinaudo publicou recentemente uma revisão sobre as principais propriedades e aplicações de polissacarídeos em biomateriais. ${ }^{15}$ A Tabela 2 apresenta exemplo de aplicações dos polissacarídeos produzidos industrialmente. Além dessas propriedades podem-se destacar outros usos importantes de alguns polissacarídeos. Dextrana é muito utilizada em sistemas de separação e purificação de substâncias na forma de resina e como substituto do plasma no sangue. ${ }^{14}$ Xantana além das aplicações alimentícias e de fronteiras também é utilizada na indústria petrolífera como lubrificante de sondas de perfuração ${ }^{14}$ e na preparação de produtos oftálmicos. ${ }^{16}$

Várias revisões bibliográficas estão disponíveis relatando o grande potencial de quitina e quitosana na preparação de novos materiais na área biomédica e farmacêuticas. ${ }^{15,47,48}$ Quitina e quitosana também possuem grande afinidade por pigmentos, íons metálicos, moléculas quirais e biomacromoléculas e são utilizadas como materiais adsorventes dessas substanciais. ${ }^{49}$

Atividades biológicas como: antivirais, antitumorais, antioxidantes, anticoagulantes e antitrombóticas também vêem sendo investigadas para polissacarídeos extraídos de diversas fontes. Os polissacarídeos presentes nos cogumelos têm sido reportados como estimuladores do sistema imunológico, atuando como antivirais, ${ }^{50}$ antioxidantes, ${ }^{51}$ e antitumorais. ${ }^{52}$ Heparina é um conhecido e muito utilizado anticoagulante. Polissacarídeos sulfatados de algas e animais invertebrados têm sido investigados como agentes anticoagulantes e antitrombóticos, devido à similaridade estrutural com a heparina.

\section{IMPORTAÇÃO E EXPORTAÇÃO DE POLISSACARÍDEOS}

\section{Comentários gerais sobre importação e exportação brasileiras}

O Brasil, no período 2001-2007, foi marcado por intenso crescimento na sua balança comercial, saindo de um pequeno déficit em 2000 para um superávit expressivo em 2007. No período, ocorreu crescimento tanto das importações quanto das exportações, mas as exportações tiveram uma taxa de crescimento superior, o que justifica a variação do superávit de 2,6 bilhões de dólares em 2001 para 40 bilhões de dólares em 2007.53

Tabela 2. Aplicações de fronteiras para polissacarídeos

\begin{tabular}{|c|c|c|c|c|c|}
\hline Polissacarídeo & Eng $^{\mathrm{a}}$ de Tecidos & Líber. de Fármaco & Imobiliz. de Células & Biossensor & Ag. Viscossupl. \\
\hline Ácido Hialurônico & 15,17 & 18 & 19 & 20 & 21 \\
\hline Alginato & 17,22 & 23 & 24 & 25 & 21 \\
\hline Agarana & 17 & - & 26 & 27 & - \\
\hline Carragenana & 15,28 & 29 & 30 & 31 & - \\
\hline Dextrana & 32 & 33 & - & 34 & - \\
\hline Goma Arábica & - & 35 & 36 & 37 & - \\
\hline Goma Alfarroba & - & 38 & 30 & - & - \\
\hline Guar & - & 38 & - & 27 & 39 \\
\hline Quitina/Quitosana ${ }^{\mathrm{a}}$ & 15,22 & 40 & 41 & 42 & 43 \\
\hline Pectina & 22 & 44 & - & 45 & - \\
\hline Xantana & - & 46 & 47 & - & - \\
\hline
\end{tabular}

${ }^{\mathrm{a}}$ ou derivados. 
Tabela 3. Polissacarídeos pesquisados e sua origem

\begin{tabular}{|c|c|c|c|}
\hline Origem & $\mathrm{N}^{\mathrm{o}}$ & Polissacarídeo & Nome na busca \\
\hline \multirow[t]{3}{*}{ Alga } & 1 & Ácido algínico & Ácido algínico, seus sais e ésteres \\
\hline & 2 & carragenana & carragenina \\
\hline & 3 & ágar & agar-agar \\
\hline \multirow[t]{2}{*}{ Planta - semente } & 4 & guar & Produtos mucilaginosos e espessantes de sementes de guare \\
\hline & 5 & alfarroba & Produtos mucilaginosos e espessantes de alfarroba \\
\hline Planta & 6 & - & Produtos mucilaginosos e espessantes de outros vegetais \\
\hline Planta - exsudato & 7 & Goma arábica & o mesmo \\
\hline \multirow[t]{2}{*}{ Planta - fruto } & 8 & pectina & pectina \\
\hline & 9 & pectina & Outros materiais pécticos, pectinatos e pectatos \\
\hline Planta - tubérculo & 10 & amido & amido \\
\hline Planta - caule & 11 & celulose & celulose \\
\hline \multirow[t]{2}{*}{ Microbiológicas } & 12 & dextrana & o mesmo \\
\hline & 13 & Goma xantana & o mesmo \\
\hline \multirow[t]{6}{*}{ Planta - derivados } & 14 & Acetato de celulose & o mesmo \\
\hline & 15 & Nitrato de celulose & o mesmo \\
\hline & 16 & Propionato de celulose & o mesmo \\
\hline & 17 & Metil, etil e propil celulose & o mesmo \\
\hline & 18 & carboximetilcelulose & o mesmo \\
\hline & 19 & Sais de carboximetilcelulose & o mesmo \\
\hline Animais & 20 & heparina & heparina e seus sais \\
\hline
\end{tabular}

Infelizmente, este dinamismo comercial não foi acompanhado de um crescimento mais intenso da economia nacional. ${ }^{54} \mathrm{~A}$ relação entre comércio exterior e crescimento depende muito do conteúdo de elaboração dos produtos e da agregação de valor que existe na produção destes bens. O setor de exportação com maior fator agregado, ou seja, aquele portador de mais inovação, é o que tem mais impacto no crescimento de uma economia. ${ }^{54} \mathrm{O}$ setor manufatureiro é tido, então, como o dinamizador do crescimento da economia como um todo. Segundo dados da SECEX,$^{55}$ a contribuição dos bens manufaturados na pauta de exportação diminuiu de 56,5 para $46,8 \%$ de 2001 para 2007.

Conclusão semelhante pode ser obtida quando se analisa os setores industriais de exportação por intensidade tecnológica. ${ }^{55}$ Primeiramente, observa-se que a contribuição dos produtos considerados não industriais cresceu de 11,5\% em 2001 para 17,1\% em 2007. Apenas dois setores com alta tecnologia encontram-se entre os 10 maiores e participação deles diminuiu de 10 para $5 \%$ no período. Esses setores são: Aeronáutica e aeroespacial e, Equipamentos de rádio, TV e comunicação. No sentido contrário estão os setores mais próximos da indústria química: Produtos Químicos (tecnologia média-alta) e Produtos de petróleo (tecnologia média-baixa), que aumentaram a participação de 8 para $9,5 \%$.

A pauta de importação brasileira apresenta forte correlação com o investimento produtivo. A maior contribuição é a dos Produtos Químicos, que representaram 15,8\% da pauta total em 2007 contra 14,5\% em 2001. ${ }^{55}$ Em seguida está o setor de Máquinas e Equipamentos Mecânicos, com 11,0\% em 2007.

\section{Importação e exportação de polissacarídeos}

\section{A sistemática de busca}

Informações referentes aos polissacarídeos mais utilizados industrialmente foram buscadas no AliceWeb. ${ }^{56}$ A Tabela 3 mostra os polissacarídeos pesquisados, a origem deles e com que grafia apareceram na busca. As informações obtidas foram importação e exportação em kg e em dólares. Gelana, ácido hialurônico, goma ghati, goma caraia, goma tragacante, quitosana e quitina - com essas grafias e outras próximas, foram também pesquisados, mas não foram encontrados registros de comércio exterior. Para simplificar a análise, os itens 8 e 9 foram reunidos, assim como 14, 15 e 16 e, também, 18 e 19.

\section{Evolução do comércio exterior de 1998 a 2007}

Os valores de importação e exportação anuais de cada polissacarídeo listado (Tabela 3) foram consolidados de 1998 a 2007. As Figuras 1a e 1b apresentam esses valores em milhões de dólares e em mil toneladas. A importação entre 1998 e 2003 não variou muito, oscilando entre 64 e 70 mi US\$ (Figura 1a). A partir daí cresceu significativamente até 2007 , alcançando 111 mi US\$. A exportação do segmento sofreu um pequeno decréscimo de 1998 a 2001, e a partir daí iniciou uma tendência crescente, com algumas oscilações, chegando em 2007 com 70 mi US\$ (Figura 1b). O incremento de 2003 para 2007 foi de $45 \%$ para a exportação, contra $69 \%$ da importação. O preço médio do produto importado em 2007 foi 4,1 US\$/kg e do exportado 2,3 US\$/kg. Em 2008, as importações de polissacarídeos cresceram e chegaram a 142 mi US\$, mas as exportações diminuíram (68 mi US\$). O país importa cada vez mais polissacarídeos do que exporta e a um custo médio superior.

Comparando-se a ordem de grandeza do recurso total da pauta de importação e exportação com a do segmento polissacarídeos, verifica-se que as respectivas contribuições são pequenas. O segmento participa na ordem de $10^{-3} \%$ na importação e na ordem de $10^{-4} \%$ na exportação. Diferentemente do comportamento da balança comercial brasileira, que é superavitária desde $2001,{ }^{53}$ o segmento apresentou déficit em todos os últimos 10 anos. Entre 1998 e 2002 ele foi em torno de $80 \%$ e entre 2003 a 2007 de $60 \%$ da pauta de exportação 

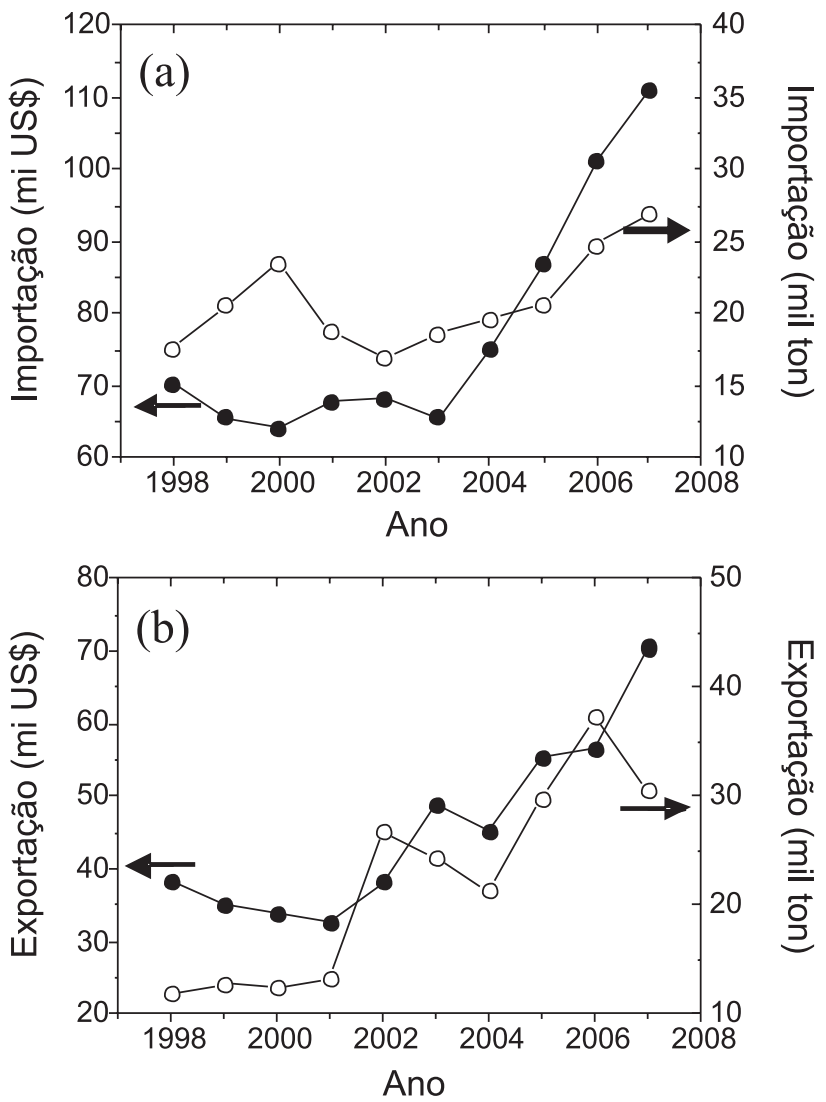

Figura 1. Evolução do comércio exterior brasileiro do segmento de polissacarídeos de 1998 a 2007 em milhões de dólares e em mil toneladas: a) importação; b) exportação

do segmento. Em 2008, a situação foi atípica, e o déficit apresentou recorde de $108 \%$

\section{Distribuição da pauta de importação e exportação por polissacarídeo}

A importação e a exportação da cada polissacarídeo individualmente ou agrupado foram acompanhadas de 2003 a 2007. Celulose e seus derivados são os produtos mais importados, representando cerca de 190 mi US $\$ / 5$ anos e 42,4\% da pauta do segmento (Figura 2a). Destacam-se, também, xantana e carragenana, com 70 e 40 mi US $\$ / 5$ anos, respectivamente. A importação de ágar, dextrana e amido é pequena, menor que $8 \mathrm{mi}$ US $\$ / 5$ anos. Os outros polissacarídeos foram importados em uma faixa de 10 a $23 \mathrm{mi}$ US $\$ / 5$ anos. $\mathrm{O}$ padrão da importação em mil ton (Figura $2 \mathrm{~b}$ ) apresenta algumas variações com relação ao da Figura $2 \mathrm{a}$. A quantidade de amido importada foi de 13 mil ton $/ 5$ anos, maior do que a quantidade de todos os outros polissacarídeos, exceto metil-, etil-, propil-celulose, e CMC e seus sais. O relativo baixo preço do amido é responsável por esse comportamento. Comportamento semelhante é o da goma guar, embora em menor proporção. No sentido inverso estão a pectina e os polissacarídeos de algas, cujo preço deve ser superior ao da média dos demais.

O perfil da exportação (Figura 3) é completamente diferente. Destacam-se: pectina, celulose, metil-, etil-, propil- celulose, CMC e seus sais e amido. A exportação de amido foi de 94,5 mil toneladas no período, seguida de celulose (19,6 mil ton), pectina (12,8 mil ton), metil-, etil- propil- celulose (9,6 mil ton) e CMC e seus sais (4,5 mil ton). Goma guar, goma arábica, e de alfarroba são extraídas de plantas de outros países, justificando a exportação quase inexistente. Alguma exportação de ácido algínico e carragenana foi registrada.

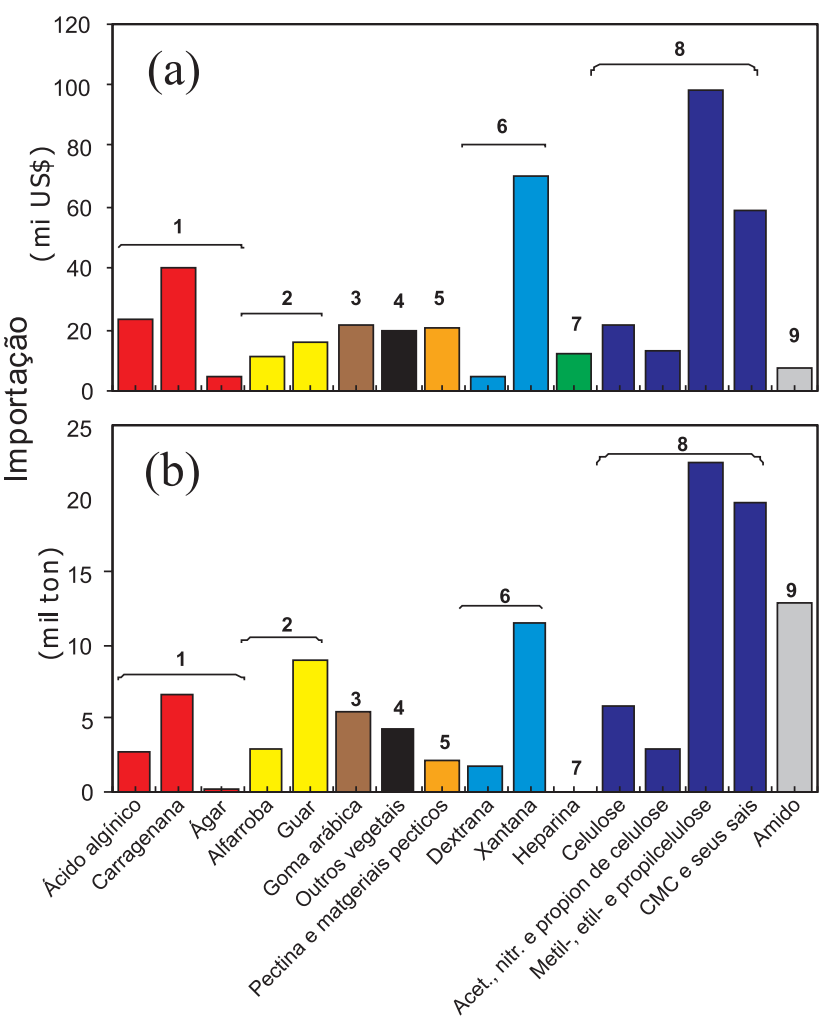

Figura 2. Importação brasileira de cada polissacarídeo em 5 anos (2003 a 2007) agrupados pela origem: a) em milhões de dólares; b) em mil toneladas. 1) alga; 2) semente; 3) exsudato; 4) vegetais não identificados; 5) pectinas; 6) microbiológica; 7) animais; 8) celulose e derivados; 9) cereais

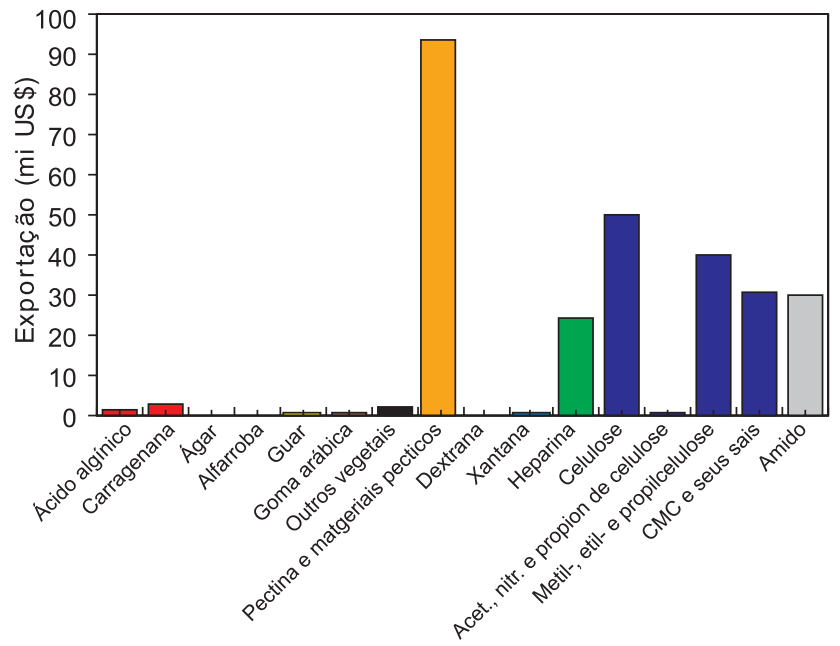

Figura 3. Exportação brasileira de cada polissacarídeo em 5 anos (2003 a 2007) em milhões de dólares

Evolução na importação e exportação de cada polissacarídeo de 1998 a 2007

Os polissacarídeos foram agrupados por origem para facilitar a análise da evolução no período, e escolhidos aqueles com maior contribuição para a pauta de importação do segmento. Os grupos foram os seguintes: grupo de algas (ácido algínico, carragenana e ágar), grupo de gomas de sementes e exsudadas (alfarroba, guar, goma arábica e outros vegetais), grupo de origem microbiológica (dextrana e xantana) e de CMC e seus sais. Heparina - por ser a única de origem animal, e o metil-, etil-, propil- celulose - pela sua grande contribuição, foram 
tratados individualmente. Na Figura 4a observa-se que a tendência de 1998 a 2002 variou com o produto. Verifica-se que todos os produtos tiveram tendência de importação crescente de 2003 a 2007. Os dados relativos ao ano de 2008 são: alga (16,8 mi US\$); metil-, etil-, propil- celulose (36,8 mi US\$); CMC e seus sais (20,8 mi US\$); microbiológicas (20,7 mi US\$); exsudatos e sementes (22,3 mi US\$) e heparina (6,3 mi US\$). A tendência continua crescente. Metil-, etil-, propil- celulose destaca-se dos demais a partir de 2005.
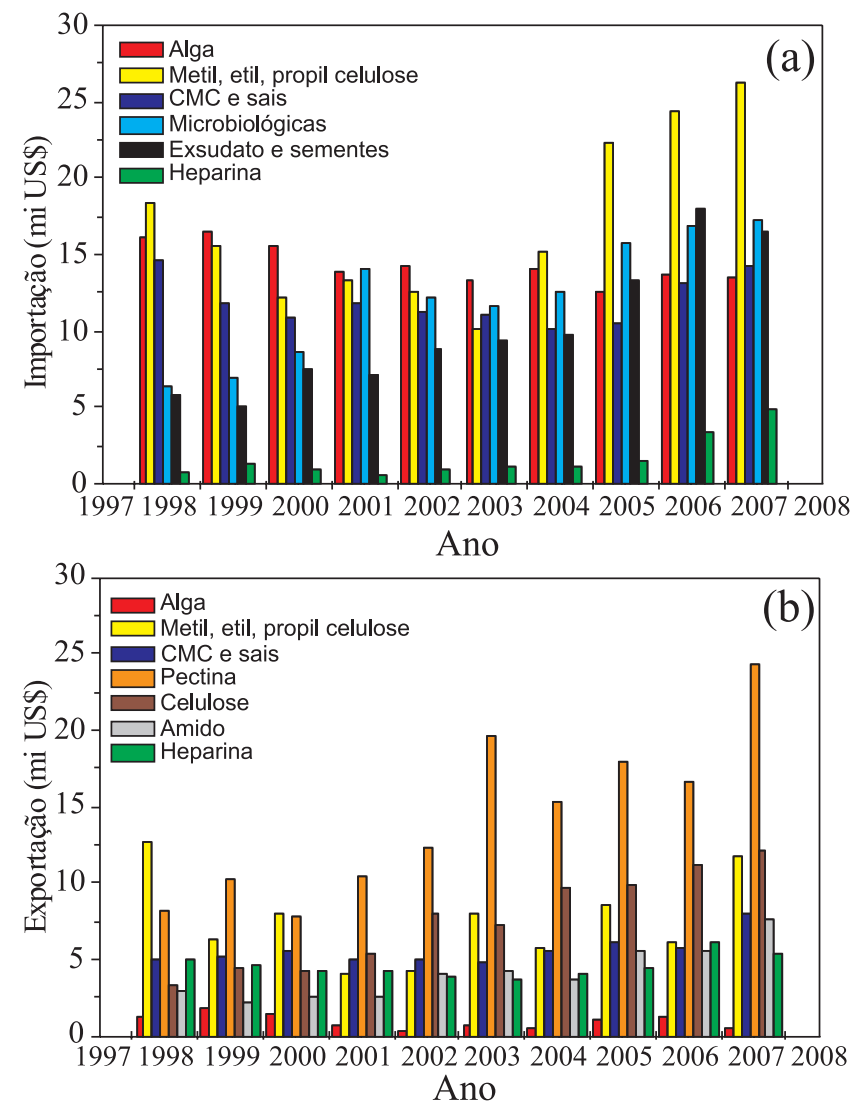

Figura 4. Evolução da importação e exportação dos polissacarídeos mais representativos de 1998 a 2007

A sistemática de agrupamento para o acompanhamento da exportação foi semelhante, mas os grupos foram diferentes. Foram eles: grupos de alga, de CMC e seus sais, de pectina. Celulose, metil-, etil-, propil- celulose, amido e heparina foram acompanhados individualmente. A situação da exportação em 2008 não é muito diferente da de 2007 (Figura 4b). A exportação de pectina destaca-se de 2001 a 2008, tendo sido a que mais cresceu de 2007 a 2008. As exportações de celulose e de CMC, que vinham em tendência crescente, ficaram mantidas em 2008. A exportação de polissacarídeos de algas é irrisória ao longo do período. Amido e, especialmente, metil-, etil-, propil- celulose, foram menos exportados em 2008, tendo sido responsáveis pelo maior déficit do segmento em 2008. Heparina, que não vinha apresentando grandes variações ao longo da década, foi mais exportada no último ano.

\section{Preços dos polissacarídeos no mercado mundial}

O preço dos polissacarídeos importados em 2007 varia consideravelmente (Tabela 4). Amido é o de custo mais baixo, a 0,71 US\$/kg, e heparina é o de custo mais elevado, a 263 US\$ $/ \mathrm{kg}$. Em média, aqueles de origem animal (heparina e condroitim sulfato) são os mais caros, seguidos pelos de alga. Os polissacarídeos de sementes e de exsudato têm preço médio entre 1,8 (guar) e 4,3 US $\$ / \mathrm{kg}$ (alfarroba). O quilo de celulose e seus derivados varia entre 3,9 e 5,4 US\$ $/ \mathrm{kg}$, mas CMC apresenta preço inferior. Dextrana é menos da metade do preço da xantana, embora ambas sejam de origem microbiológica. Em 2008, observou-se aumento de, em média, $20 \%$ no preço dos polissacarídeos de alga. A goma arábica, também aumentou de preço, chegando a 4,5 US\$/kg. Goma de alfarroba, guar, pectina, dextrana, acetato de celulose e propionato de celulose mantiveram o preço. Xantana e heparina diminuíram de preço, essa última alcançando $135 \mathrm{US} \$ / \mathrm{kg}$.

Tabela 4. Comparação entre preço de importação e exportação de polissacarídeos

\begin{tabular}{|c|c|c|c|c|c|}
\hline \multicolumn{2}{|c|}{ Polissacarídeo } & \multicolumn{2}{|c|}{$\begin{array}{l}\text { Importação } \\
\text { (US\$/kg) }\end{array}$} & \multicolumn{2}{|c|}{$\begin{array}{c}\text { Exportação } \\
\text { (US\$/kg) }\end{array}$} \\
\hline & & 2007 & 2008 & 2007 & 2008 \\
\hline \multirow[t]{3}{*}{ Alga } & Ácido algínico & 7,8 & 9,6 & 16 & 8,4 \\
\hline & Carragenana & 6,3 & 8,1 & 8,5 & 7,2 \\
\hline & Ágar & 18 & 20,9 & 16 & 20,4 \\
\hline \multirow[t]{2}{*}{ Semente } & Alfarroba & 4,3 & 4,2 & - & - \\
\hline & Guar & 1,8 & 1,9 & - & - \\
\hline Exsudato & Goma Arábica & 3,9 & 4,5 & - & - \\
\hline Fruto & Pectina & 8,8 & 8,8 & 7,2 & 8,0 \\
\hline \multirow[t]{2}{*}{ Bactéria } & Dextrana & 2,4 & 2,4 & - & - \\
\hline & Xantana & 5,3 & 4,9 & - & - \\
\hline \multirow[t]{2}{*}{ Animal } & Heparina & 263 & 135 & 942 & 1668 \\
\hline & Condroitim sulfato & 37 & 34,3 & - & - \\
\hline \multirow[t]{6}{*}{ Caule } & Celulose & 3,9 & 4,8 & 2,6 & 2,8 \\
\hline & Acetato de celulose & 5,4 & 5,3 & - & - \\
\hline & Nitrato de celulose & 4,2 & - & - & - \\
\hline & $\begin{array}{l}\text { Propionato de } \\
\text { celulose }\end{array}$ & 4,3 & 4,4 & - & - \\
\hline & $\begin{array}{l}\text { Metil, etil, propil } \\
\text { celulose }\end{array}$ & 4,3 & 5,3 & 4,6 & 4,5 \\
\hline & $\mathrm{CMC}^{*}$ e sais & 2,9 & 3,3 & 7,1 & 7,1 \\
\hline Cereais & Amido & 0,71 & 0,40 & 0,42 & 0,58 \\
\hline
\end{tabular}

* Carboximetilcelulose. Valores calculados a partir do Aliceweb ${ }^{56}$

Os preços dos produtos exportados são diferentes dos praticados na importação. $\mathrm{O}$ destaque é para a heparina, cujo preço de exportação, tanto em 2007 como em 2008, foi muito superior ao de importação. Na mesma tendência estão os polissacarídeos de algas e CMC. O preço do amido depende da origem. O Brasil exporta, fundamentalmente, amido de milho e importa tanto amido de milho, como de trigo.

\section{POLISSACARÍDEOS DA BIODIVERSIDADE BRASILEIRA}

O Brasil possui um grande grupo de pesquisadores dedicados à caracterização e teste de propriedades de polissacarídeos oriundos de diversas fontes. Alguns resultados, dos muitos disponíveis, serão descritos a seguir.

\section{Polissacarídeos de sementes}

Galactomananas e xiloglucanas da flora brasileira vêm sendo caracterizadas por diferentes grupos de pesquisa. A Tabela 5 apresenta 
Tabela 5. Aplicações testadas para galactomananas brasileiras

\begin{tabular}{lcc}
\hline Origem & Aplicações & Ref. \\
\hline Mimosa scabrella & Formulações de xampu, pudim & 57 \\
& Matriz cromatográfica para isol. & 58 \\
& Me lectina & \\
& Antriz para liberação de fármaco & 59 \\
& Antiviral: febre amarela & 60 \\
\hline Adenanthera & Filmes & 61 \\
pavonina & Liberação de fármaco & 62 \\
\hline Leucena & Micropropagação plantas & 63 \\
leucocephala & Filmes finos & 64 \\
& Absorção de albumina & 65 \\
\hline Dimorphandra & Antiviral: febre amarela & 60 \\
mollis & Aditivo na produção de papel & 66 \\
\hline Caesalpinia & Meio de cultura de fungos & 67 \\
pulcherrina & Filmes finos & 64 \\
& Filmes para revestimento de frutos & 68 \\
\hline $\begin{array}{l}\text { Schizolobium } \\
\text { parahybum }\end{array}$ & Matriz cromatográfica para isol. de & 69 \\
\hline Cassia fastuosa & lectina & 63 \\
\hline Cassia siliqua & Matriz cromatográfica para isol. & 69 \\
\hline & Micropropagação de plantas & 60 \\
\hline
\end{tabular}

aplicações para galactomananas de sementes brasileiras já caracterizadas. As gomas de Caesalpinia pulchessina ${ }^{71}$ e Cássia javanica ${ }^{71}$ possuem razão manose/galactose próxima à da goma de alfarroba ( 3:1) e rendimentos de extração compatíveis com os obtidos industrialmente, 25 e $26 \%$, respectivamente. A goma da Dimorphandra gardneriana, conhecida popularmente como fava d'anta, apresenta razão $\mathrm{M} / \mathrm{G}$ muito próxima à da goma guar e rendimento de $31 \%$ na sua extração. ${ }^{72} \mathrm{~A}$ fava d' anta é nativa do cerrado e é utilizada para extração da rutina, um flavonoide com ação antioxidante e anti-inflamatório. Nesse processo cerca de 600 toneladas de sementes são descartadas por ano, o suficiente para produzir aproximadamente 160 ton/ano da galactomanana somente com o rejeito, ${ }^{72}$ substituindo parte da exportação de goma guar comercial e com maior grau de pureza.

No Brasil, as espécies nativas como Hymenaea courbaril, ${ }^{73}$ Copaifera lansdorfii ${ }^{74}$ e Mucuna sloanei ${ }^{75}$ são fontes potenciais de xiloglucanas para diferentes aplicações. Esses polissacarídeos possuem resposta imunomodulatória. ${ }^{76}$ Xiloglucanas de $H$. courbaril, ${ }^{73}$ C. Lansdorfii foram utilizadas na preparação de filmes finos. ${ }^{77} \mathrm{O}$ polissacarídeo da $H$. courbaril foi utilizado para micropropagação de plantas. $^{78}$

\section{Polissacarídeos de algas marinhas}

Polissacarídeos de algas marinhas são importantes fontes de matérias-primas utilizadas nas indústrias alimentícia e farmacêutica. Na indústria alimentícia, a busca é por um agente geleificante. Para a área farmacêutica, eles apresentam as seguintes atividades biológicas: antivirais, antitrombótica, anticoagulantes e antitumorais. A Tabela 6 apresenta polissacarídeos de diversas algas brasileiras. Algumas

Tabela 6. Polissacarídeos de algas brasileiras e sua atividade biológica

\begin{tabular}{|c|c|c|c|}
\hline Tipo de Algas/ Tipo de Polissacarídeo & Espécies & Atividade Biológica & Ref \\
\hline \multicolumn{4}{|l|}{ Algas Vermelhas } \\
\hline \multirow[t]{4}{*}{ Carragenanas } & Maristella gelidium & Antiviral: dengue e herpes & 79 \\
\hline & Hypnea musciformis & & 80 \\
\hline & Gymnogongrus griffthsiae & Antiviral: dengue e herpes & 81 \\
\hline & Botryocladia occidentais & - & 82 \\
\hline \multirow[t]{6}{*}{ Agaranas } & Gracilaria birdiae & - & 83 \\
\hline & Gracilaria domingensis & - & 84 \\
\hline & Gracilaria cornea & - & 84 \\
\hline & Porphyra spiralis & - & 86 \\
\hline & Bostrychia montagnei & Antiviral: herpes & 87 \\
\hline & Acanthophora spicifera & Antiviral: herpes & 88 \\
\hline Galactanas híbridas & Cryptonemia crenulata & Antiviral: dengue e herpes & 89 \\
\hline \multirow[t]{5}{*}{ Fucanas } & Dyctyota menstrualis & - & 90 \\
\hline & Dyctyota mertensii & - & 91 \\
\hline & Padina gymnospora & - & 91 \\
\hline & Spatoglossum schröederi & Anticoagulante e Antitrombótica & 92,93 \\
\hline & Sargassum stenophyllum & Antiviral: herpes, Antitumoral & 94 \\
\hline \multirow[t]{3}{*}{ Alginato } & Sargassum stenophyllum & - & 95 \\
\hline & Sargassum vulgare & Antitumoral & 96,97 \\
\hline & Laminaria brasiliensis & - & 98 \\
\hline \multicolumn{4}{|l|}{ Algas Verdes } \\
\hline & Codium isthmocladum & Anticoagulante & 99 \\
\hline & Ulva pertusa & Anti-hiperlipidêmica & 100 \\
\hline & Ulva rigida & Imunomoduladora & 101 \\
\hline & Monostroma sp & Anticoagulante, Antiviral & 102 \\
\hline & Gayralia oxysperma & Antiviral: herpes & 103 \\
\hline
\end{tabular}


algas podem se reproduzir facilmente em criatórios naturais, como é o caso da Gracilaria birdeae, que está sendo produzida no Ceará por pescadores, com o envolvimento da UFC, UNIFOR e da ONG Terramar.

\section{Polissacarídeo de exsudatos}

Polissacarídeos de exsudatos de algumas árvores brasileiras, em especial nativas do Nordeste, já foram estudados. Foram elas: cajueiro (Anacardium occidentale), ${ }^{104-106}$ angico (Anadenanthera macrocarpa), ${ }^{107}$ timbaúba (Enterolobium contortisilliqum), ${ }^{108}$ Albizia lebbeck, ${ }^{109}$ ciriguela (Spondia purpurea) $)^{110}$ e chichá (Sterculia striata). ${ }^{111,112}$ Todos eles apresentam galactose e acido urônico, embora em teores bem diferentes. A goma do chichá, por exemplo, é a que contém o maior teor de grupamentos ácido (quase 50\%) e é, também, a mais viscosa. As demais têm abaixo de $17 \%$ desse constituinte. Arabinose é outro constituinte comum nas gomas de exsudatos.

Com o objetivo de ampliar as possibilidades de aplicação dessas gomas, modificações estruturais têm sido realizadas. Inserção de grupos carboxilato, ${ }^{113,114}$ oxidação dos grupos hidroxila a ácido, ${ }^{115} \mathrm{e}$ enxertia com acrilamida ${ }^{116}$ são algumas das modificações feitas.

A goma do cajueiro apresenta uma grande possibilidade de produção comercial. A área cultivada com cajueiro, segundo o IBGE, em 2006 era de 710.404 hectares. ${ }^{117}$ A exsudação da goma é simples e muitas vezes espontânea. A produção média de goma/planta/ano é de 700 g. ${ }^{118}$ Tomando em consideração que o adensamento médio é de 100 plantas/hectare a possibilidade de produção da goma/ano seria de 50.000 toneladas, quantidade muito superior à importada de goma arábica, por exemplo, em 2008 (6.700 ton). Seria uma forma de agregar valor à cajucultura, desde que existisse mercado para a goma.

Algumas aplicações de gomas de exsudatos têm sido propostas nos últimos anos. Polissacarídeo da $S$. purpurea (ciriguela) foi reticulado e utilizado como matriz cromatográfica para separação de lectinas. ${ }^{110}$ A goma do angico e o angico carboximetilado foram reticulados e utilizados como matriz para adsorção de metal pesado. ${ }^{114}$ Nanopartículas de goma de angico/ácido acrílico também foram sintetizadas e caracterizadas. ${ }^{119}$ A Tabela 7 apresenta aplicações da goma do cajueiro.

\section{Outros polissacarídeos}

Invertebrados marinhos, fungos e liquens são fontes de polissacarídeos que apresentam atividades biológicas e podem representar uma fonte para a indústria brasileira de anticoagulante, antitrombóticos e substâncias antitumorais. Vários grupos de pesquisa vêm se dedicando ao estudo de polissacarídeos extraídos de invertebrados marinhos, ${ }^{137-143}$ liquens ${ }^{144,145}$ e fungos, especificamente de cogumelos. ${ }^{146-150}$ De alguns invertebrados marinhos foram extraídos heparina e derivados com atividade anticoagulante. ${ }^{143,151} \mathrm{~A}$ mesma atividade foi detectada em galactana sulfatada, ${ }^{152}$ condroitim sulfato glicosilado $^{153}$ e dermatam sulfato, ${ }^{154,155}$ também extraídos de invertebrados marinhos. Atividade antitumoral foi apresentada por $\alpha$-glucana ${ }^{156} \mathrm{de}$ liquens. Do cogumelo Agaricus blazei foi extraída $\alpha$ e $\beta$-glucana, ${ }^{149}$ com atividade antitumoral ${ }^{148} \mathrm{e}$ antimutagênica. ${ }^{150}$

O Agaricus blazei, que é um cogumelo comestível - conhecido popularmente como cogumelo do sol, representa um caso emblemático. Ele é oriundo das regiões serranas do sul do estado de São Paulo. ${ }^{157}$ Entre agosto de 2006 e setembro de 2008, o Brasil exportou 1,7 ton do cogumelo bruto, com uma receita de 148 mil dólares. Dele poderiam ser extraídos polissacarídeos de elevado valor econômico e de nobres aplicações, como a $\beta$-glucana, transformando assim conhecimento da nossa biodiversidade em valor econômico significativo.
Tabela 7. Algumas aplicações para a goma do cajueiro e derivados

\begin{tabular}{|c|c|c|}
\hline Área & Aplicação & Ref. \\
\hline \multirow[t]{4}{*}{ Alimentos } & Microencapsulação de extrato de café & 120 \\
\hline & Emulsão em saladas & 121 \\
\hline & Estabilizante em suco de caju & 122 \\
\hline & Fabricação de salsichas & 123 \\
\hline \multirow[t]{5}{*}{ Saúde } & Atividade antimicrobiana & 124 \\
\hline & $\begin{array}{l}\text { Atividade antitumoral in vivo em } \\
\text { camundongos }\end{array}$ & 125 \\
\hline & $\begin{array}{l}\text { Efeito no processo cicatricial de lesões } \\
\text { cutâneas }\end{array}$ & 126 \\
\hline & $\begin{array}{l}\text { Géis e microesferas para liberação de } \\
\text { fármaco }\end{array}$ & $\begin{array}{l}127 \\
128\end{array}$ \\
\hline & Atividade antirotavirus & 129 \\
\hline Mineral & $\begin{array}{l}\text { Depressor na flotação de minerais } \\
\text { fosfatados }\end{array}$ & 130 \\
\hline Agricultura & Hidrogel superabsorvente & $\begin{array}{l}131, \\
132 \\
\end{array}$ \\
\hline Biotecnologia & $\begin{array}{l}\text { Encapsulação de droga de combate à } \\
\text { dengue }\end{array}$ & 133 \\
\hline \multirow[t]{3}{*}{ Nanotecnologia } & Emulsificante de nanotubos de carbono & 134 \\
\hline & Nanopartícula com quitosana & 135 \\
\hline & $\begin{array}{l}\text { Imobilização de Concanavalina A em } \\
\text { filmes finos }\end{array}$ & 136 \\
\hline
\end{tabular}

Quitina é um dos mais abundantes polissacarídeos ${ }^{158,159}$ na biomassa de crustáceos, principalmente camarões, caranguejos e lagostas. É um polissacarídeo bioativo, biodegradável, biocompatível e atóxico. A sua insolubilidade na maioria dos solventes comuns faz com que sua maior aplicação seja na produção de quitosana, geralmente obtida pela desacetilação alcalina de quitina. A quitosana é um polímero hidrofílico que exibe atividades antimicrobiana e hemostática, afinidade por diferentes substâncias, tais como: íons metálicos, herbicidas, pesticidas, corantes, proteínas, lipídeos e polímeros, e a capacidade de formar filmes, membranas e géis. Sendo assim, ela tem aplicação na adsorção e remoção de íons metálicos ${ }^{160-162}$ e corante, ${ }^{163}$ em dispositivo tipo "língua eletrônica", ${ }^{164}$ biossensor para determinação de rutina, ${ }^{165}$ preparação de géis para liberação de fármacos ${ }^{128,166,167}$ e de larvicida ${ }^{168}$ e de nanopartículas para liberação oral de insulina. ${ }^{169-171}$

Pectina - produto do segmento mais exportado, é objeto de poucas pesquisas no país. ${ }^{172,173}$ Ela é normalmente extraída de casca de frutas cítricas e maçã, mas pode ser obtida de outros frutos, como maracujá. As empresas produtoras do Brasil normalmente utilizam frutas cítricas e, por essa razão, algumas se localizam no estado de São Paulo, próximo da matéria-prima. Outras matérias-primas abundantes em outras regiões poderiam ser pesquisadas e caracterizadas, verificandose a viabilidade econômica e técnica da extração.

\section{BIODIVERSIDADE NA INDÚSTRIA}

Ferro, Bonacelli e Assad discutiram as oportunidades oferecidas pelo uso sustentável da biodiversidade como estratégia competitiva e analisaram os casos de quatro empresas nacionais - Ybios, Centroflora, Orsa Florestal e Natura. ${ }^{174}$ A Ybios é uma empresa de identificação de novas oportunidades de uso de produtos naturais e gestão de projetos 
de bioprospecção, resultado de uma joint-venture das três outras empresas. Os autores concluíram que a incorporação do desenvolvimento sustentável precisa estar inserida na política de responsabilidade socioambiental da empresa, para ela ser um caso de sucesso.

Para transformar biodiversidade em valor econômico e bemestar da população, e utilizando o caso das empresas analisadas, é necessário que as seguintes etapas sejam cumpridas: a) prospecção de novas oportunidades de negócio a partir do conhecimento disponível no setor acadêmico ou da demanda de mercado; b) identificação de competências científicas; c) formação de redes de pesquisa; d) estabelecimento de parcerias entre a empresa, pequenos agricultores, comunidades extrativistas, órgãos do governo, universidades e institutos de pesquisa.

\section{CONSTATAÇÕES}

Algumas constatações foram obtidas analisando-se a exaustiva, mas ainda incompleta, busca. São elas:

a) O Brasil apresenta um déficit na balança comercial no segmento de polissacarídeos, em contradição com o superávit na pauta total de comércio exterior.

b) Os diversos grupos de pesquisa no país já promovem eficientemente o desenvolvimento científico do segmento e podem ser facilmente identificados.

c) Pesquisa insuficiente é feita para transformar o conhecimento científico acumulado em inovação tecnológica, desafio também de muitas outras áreas.

d) Existe um distanciamento entre os grupos de pesquisa - que estudam polissacarídeos do seu próprio interesse, e as empresas - que produzem e exportam polissacarídeos que o mercado precisa, espaço que necessita urgentemente ser preenchido.

e) Existe a possibilidade concreta de produção de alguns polissacarídeos, que podem ser uma alternativa a produtos existentes, ou representarem novos produtos.

\section{CONSIDERAÇÕES FINAIS}

O país tem todas as condições para transformar o conhecimento em polissacarídeos da sua biodiversidade em valor econômico e bem-estar da população, sem prejuízo da sustentabilidade ambiental. A formação de parcerias e redes de competências entre o setor acadêmico e a indústria é essencial, assim como políticas públicas capazes de incentivar uma postura ambientalmente correta por parte da indústria. O momento é agora, quando a inovação, o desenvolvimento regional e o ambiental são prioridade. ${ }^{175}$

\section{AGRADECIMENTOS}

Ao querido Prof. F. J. de A. Matos, UFC, por uma vida de dedicação aos produtos naturais - que atraiu muitos seguidores, e por ter conseguido transformar biodiversidade em bem-estar de populações carentes, através da implantação de inúmeras farmácias-vivas. Os autores agradecem, também, à Rede Nanoglicobiotec/CNPq.

\section{REFERÊNCIAS}

1. Arnt, R.; Exame 2001, ano 35, n. 9 .

2. Lewinsohn, T.; Prado, P. I.; Biodiversidade brasileira: síntese do estado atual do conhecimento, Editora Contexto: São Paulo, 2002.

3. Salati, E.; Santos, A. A.; Klabin, I.; Est. Avanç. 2006, 20, 56.

4. Vogt, C.; Biodiversidade: a vida e seus semelhantes, disponível em www.comciencia.br/reportagens/biodiversidade/bio01, acessada em Janeiro 2009.
5. Stephen, A. M.; Phillips, G. O.; Williams, P. A., eds.; Food Polysaccharides and their applications, $2^{\text {nd }}$ ed., CRC Press : Florida, 2006, Caps. 1,7 e 8.

6. Em ref. 5, Cap. 6.

7. Edwards, M.; Bulpin, P. V.; Dea, I. C. M.; Reid, J. S. G.; Planta 1989, $178,41$.

8. Em ref. 5, Cap. 13.

9. BeMiller, J. N. Em An Introduction to Pectin: structure and properties. Chemistry and Functions of Pectin; Fishman, M. L.; Jen, J. J., eds., American Chemical Society: Washington DC, ACS Symposium Series, 1986, n. 310, p. 2.

10. Axelos, M. A. V.; Lefebvre, J.; Qiu, C. G.; Rao, M. A. Em Rheology of pectin dispersion and gels. The chemistry and technology of pectin; Walter, R. H., ed., Academic Press: San Diego, 1991, p. 228.

11. Em ref. 5, Cap. 2 e 10.

12. Olafsdottir, E. S.; Ingólfsdottir, K.; Planta Med. 2001, 67, 99.

13. Zhang, M.; Cui, S. W.; Cheung, P. C. K.; Wang, Q.; Trends Food Sci. Technol. 2007, 18, 4.

14. Sutherland, I. W. Em Polysaccharides: structural diversity and functional versatility; Dumitriu, S., ed.; Marcel Dekker: New York, $2^{\text {nd }}$ ed., 2005, Cap. 16.

15. Rinaudo, M.; Polym. Int. 2008, 57, 397.

16. Ceulemans, J.; Vinckier, I.; Ludwig, A.; J. Pharm. Sci. 2002, 91, 1117.

17. Chajra, H.; Rousseau, C. F.; Cortial, D.; Ronzieree, M. C.; Herbage, D.; Mallein-Gerin, F.; Freyria, A. M.; Bio-Med. Mater. Eng. 2008, 18, S33.

18. Jain, A.; Jain, S. K.; Eur. J. Pharm. Sci. 2008, 35, 404.

19. Morra, M.; Exoert Rev. Med. Devices 2007, 4, 361.

20. Tanaka, M.; Sackmann, E.; Phys. Status Solidi A 2006, 203, 3452.

21. Pelletier, S.; Hubert, P.; Payan, E.; Marchal, P.; Choplin L.; Dellacherie, E.; J. Biom. Mater. 2001, 54, 102.

22. Boateng, J. S.; Matthews, K. H.; Stevens, H. N. E.; Eccleston, G. M.; J. Pharm. Sci. 2008, 97, 2892.

23. Degim, I. T.; Celebi, N.; Curr. Pharm. Des. 2007, 13, 99.

24. Murua, A.; Portero, A.; Orive, G.; Hernandez, R. M.; de Castro, M.; Pedraz, J. L.; J. Controlled Release 2008, 132, 76

25. Ding, C. F.; Zhang, M. L.; Zhao, F.; Zhang, S. S.; Anal. Biochem. 2008, $378,32$.

26. Valdman, E.; Gutz, I. G. R.; Sens. Actuators B 2008, 133, 656.

27. Bagal-Kestwal, D.; Karve, M. S.; Kakade, B.; Pillai, V. K.; Biosens. Bioeletron. 2008, 24, 657.

28. Ferreira, B. M.; Sousa, R. A.; Reis, R. L.; Tissue Eng. Part A 2008, 14, 837.

29. Bonforini, M. C.; Sandri, G.; Rossi, S.; Ferrari, F.; Caramella, C.; Aguzzi, C.; Viseras, C.; Drug Dev. Ind. Pharm. 2008, 34, 1188.

30. Sodini, I.; Boquien, C. Y.; Corrieu, G.; Lacroix, C.; J. Ind. Microbiol. Biotechnol. 1997, 18, 56.

31. Held, M.; Schuhmann, W.; Jahreis, K.; Schmidt, H. L.; Biosens. Bioeletron. 2002, 17, 1089.

32. Liu, Y. X.; Chan-Park, M. B.; Biomaterials 2009, 30, 196.

33. Liu, Z.; Jiao, Y.; Wang, Y.; Zhou, C.; Zhang, Z.; Adv. Drug Delivery Rev. 2008, 60, 1650

34. Cho, H. M.; Jang, D. H.; Lee, S. K.; Ku, S. J.; Kim, H. C.; Yu, K. S.; Lee, J. H.; Biochip. J. 2008, 2, 206.

35. Nishi, K. K.; Antony, M.; Jayakrishnan, A.; J. Pharm. Pharmacol. 2007, $59,485$.

36. Ramakrishnan, A.; Pandit, N.; Badgujar, M.; Bhaskar, C.; Rao, M.; Bioresour. Technol. 2007, 98, 368.

37. Tiwari, A.; J. Macromol. Sci. Part-A: Pure Appl. Chem. 2007, 44, 735.

38. Coviello, T.; Alhaique, F.; Dorigo, A.; Matricardi, P.; Grassi, M.; Eur. J. Pharm. Biopharm. 2007, 66, 200. 
39. Castro, R. R.; Feitosa, J. P. A.; da Cunha, P. L. R.; da Rocha, F. A. C.; Clin. Rheum. 2007, 26, 1312.

40. Varshosaz, J.; Expert Opin. Drug Delivery 2007, 4, 263.

41. Karakecli, A. G.; Satriano, C.; Gumusderelioglu, M.; Marletta, G.; Acta Biomater. 2008, 4, 989.

42. Odaci, D.; Timur, S.; Telefoncu, A.; Sens. Actuators B 2008, 134, 89.

43. Wang, W.; J. Mater. Sci.- Mater. Med. 2006, 17, 1259.

44. Liu, L. S.; Fishman, M. L.; Hicks, K. B.; Cellulose 2007, 14, 15.

45. Sungur, S.; Gunendi, G.; Polym.-Plast.-Technol Eng. 2006, 45, 527.

46. Fan, H. Y.; Wang, K.; Liu, M. M.; He, Z. M.; Carbohydr. Polym. 2008, $73,241$.

47. Dumitriu, S., ed.; Polysaccharides: structural diversity and functional versatility, Marcel Dekker: New York, $2^{\text {nd }}$ ed., 2005, Cap. 27, p. 633660; Cap. 28, p. 661-677.

48. Kumar, R. M. N. V.; Muzzareli, R. A. A.; Muzarelli, C.; Sashiwa, H.; Domb, A. J.; Chem. Rev. 2004, 104, 6017.

49. Li, C. B.; Hein, S.; Wang, K.; Mater. Sci. Technol. 2008, 24, 1088.

50. Sakurai, T.; Ohno, N.; Suzuki, I.; Yadomae, T.; Immunopharmacology 1995, 30, 157.

51. Lo, K. M.; Cheung, P. C. K.; Food Chem. 2005, 89, 533.

52. Ebina, T.; Fujimiya, Y.; Biotherapy 1998, 11, 289.

53. www.portalbrasil.net/economia_balancacomercial.htm, acessada em Janeiro 2009.

54. Baltar, C. T.; Econ. Soc. 2008, 17, 107.

55. http://www.desenvolvimento.gov.br/arquivos, SECEX, Ministério do Desenvolvimento, Indústria e Comércio Exterior, acessada em Janeiro 2009.

56. http://www.aliceweb.desenvolvimento.gov.br, acessada de Dezembro 2008 a Janeiro 2009.

57. Sugui, J. A.; Dissertação de Mestrado, Universidade Federal do Paraná, Brasil, 1994.

58. Bezerra, G. P.; Teixeira-Sá, D. M. A.; Soares, D. L.; Moreira, R. A.; XXXV Reunião Anual da Sociedade Brasileira de Bioquímica, Águas de Lindóia, Brasil, 2006.

59. Vendruscolo, C. W.; Andreazza, I. F.; Ganter, J. L. M. S.; Ferrero, C.; Bresolin, T. M. B.; Int. J. Pharm. 2005, 296, 1.

60. Ono, L.; Wollinger, W.; Rocco, I. M.; Coimbra, T. L. M.; Gorin, P. A. J.; Sierakowski, M-R.; Antiviral Res. 2003, 60, 201.

61. Figueiro, S. D.; Góes, J. C.; Moreira, R. A.; Sombra, A. S. B.; Carbohydr. Polym. 2004, 56, 313.

62. Abreu, R. F.; Moreira, R. A.; Monteiro-Moreira, A. C. O.; XXXV Reunião Anual da Sociedade Brasileira de Bioquímica, Águas de Lindóia, Brasil, 2006.

63. Lucyszyn, N.; Quoirin, M.; Koehler, H. S.; Reicher, F.; Sierakowski, M.-R.; Sci. Horticulturae 2006, 107, 358.

64. Sierakowski, M.-R.; Freitas, R. A.; Fujimoto, J.; Petri, D. F. S.; Carbohydr. Polym. 2002, 49, 167.

65. Valenga, F.; Dissertação de Mestrado, Universidade Federal do Paraná, Brasil, 2007.

66. Lima, D. U.; Oliveira, R. C.; Buckeridge, M. S.; Carbohydr. Polym. 2003, 52, 367.

67. Mesquita, J. C.; Santana, A. A.; Reis, M. C.; Lima, H. S.; Silva, A. M.; Reis, T. M.; Soares, G. M.; Muniz, W. F.; Garros-Rosa, I.; VI Reunião Regional Nordeste da Sociedade Brasileira de Bioquímica, Fortaleza, Brasil, 2002.

68. Cerqueira, M. A.; Lima, A. M. P.; Monteiro-Moreira, A. C. O.; Moreira, H. H. T.; Vicente, A. A.; Teixeira, J. A.; Moreira, R. A.; XXXV Reunião Anual da Sociedade Brasileira de Bioquímica, Águas de Lindóia, Brasil, 2006.

69. Matos, V. C.; Tese de Doutorado, Universidade Federal do Ceará, Brasil, 2000.

70. Beck, A. W.; Holloway, S. E.; Ganter, J. L. M. S.; Eberhart, R. C.; Nelson, K. D.; Fleming, J. B.; J. Surgical Res. 2004, 121, 330.
71. Azero, E. G.; Andrade, C. T.; Polym. Test. 2002, 21, 551.

72. Cunha, P. L. R.; Vieira, I. G. P.; Arriaga A. M. C.; de Paula, R. C. M.; Feitosa, J. P. A.; Food Hydrocolloids 2008, 23, 880.

73. Lima-Nishimura, N.; Reicher, F.; Corrêa, J. B. C.; Ganter, J. L. M. S.; Sierakowski, M.-R.; Ciência e Cultura 1995, 45, 22.

74. Buckeridge, M. S.; Rocha, D. C.; Reid, J. S. G.; Dietrich, S. M. C.; Physiol. Plant. 1992, 86, 145.

75. Teixeira, D. M. A.; Tese de Doutorado, Universidade Federal do Ceará, Brasil, 2005.

76. Rosário, M. M. T.; Noleto, G. R.; Bento, J. F.; Reicher, F.; Oliveira, M. B. M.; Petkowicz, C. L. O.; Phytochemistry 2007, 69, 464.

77. Sierakowski, M.-R.; Castro, L. B. R.; Lucyszyn, N.; Petri, D. F. S.; J. Braz. Chem. Soc. 2007, 18, 1017.

78. Lima-Nishimura, N.; Quoirin, M.; Naddaf, Y. G.; Wilhelm, H. M.; Ribas, L. L. F.; Sierakowski, M.-R.; Plant Cell Rep. 2003, 21, 402.

79. Faria-Tischer, P. C. S.; Noseda, M .D.; Sierakowski, M. R.; Freitas, R. A.; Duarte, M. E. R.; Carbohydr. Polym. 2006, 65, 49.

80. Saito, R. M.; Oliveira, E. C.; Hydrobiologia 1990, 204/205, 585.

81. Talarico, L. B.; Pujol, C. A.; Zibetti, R. G. M.; Faria, P. C. S.; Noseda, M. D.; Duarte, M. E. R.; Damonte, E. B.; Antiviral Res. 2005, 66, 103.

82. Melo, F. R.; Pereira, M. S.; Foguel, D.; Mourão, P. A. S.; J. Biol. Chem. 2004, 279, 20824.

83. Maciel, J. S.; Chaves, L. S.; Souza, B. W. S.; Teixeira, D. I. A.; Freitas, A. L. P.; Feitosa, J. P. A.; de Paula, R. C. M.; Carbohydr. Polym. 2008, $71,559$.

84. Guimarães, M.; Viana, A. G.; Duarte, M. E. R.; Ascêncio, S. D.; Plastino, E. M.; Noseda, M. D.; Bot. Mar. 2007, 50, 314.

85. Melo, M. R. S.; Feitosa, J. P. A.; Freitas, A. L. P.; de Paula, R. C. M.; Carbohydr. Polym. 2002, 49, 491.

86. Noseda, M. D.; Viana, A. G.; Duarte, M. E. R.; Cerezo, A. S.; Carbohydr. Polym. 2000, 42, 301.

87. Duarte, M. E. R.; Noseda, M. D.; Cardoso, M. A; Tulio, S.; Cerezo, A. S.; Carbohydr. Res. 2002, 337, 1137.

88. Duarte, M. E. R.; Cauduro, J. P.; Noseda, D. G.; Noseda, M. D.; Gonçalves, A. G.; Pujol, C.; Damonte, E.; Cerezo, A. S.; Carbohydr. Res. 2004, 339, 335.

89. Zibetti, R. G. M.; Noseda, M. D.; Cerezo, A. S.; Duarte, M. E. R.; Carbohydr. Res. 2005, 340, 711.

90. Albuquerque, I. R. L.; Queiroz, K. C. S.; Alves, L. G.; Santos, E. A.; Leite, E. L.; Rocha, H. A. O.; Braz. J. Med. Biol. Res. 2004, 37, 167.

91. Dietrich, C. P.; Farias, G. G. M.; de Abreu, L. R. D.; Leite, E. L.; da Silva, L. F.; Nader, H. B.; Plant. Sci. 1995, 108, 143.

92. Rocha, H. A. O.; de Medeiros Bezerra, L. C. L.; de Albuquerque, I. R. R.; Costa, L. S.; Guerra, C. M. P.; de Abreu, L. D.; Nader, H. B.; Leite, E. L.; Plant. Med. 2005, 71, 379.

93. Rocha, H. A. O.; Moraes, F. A.; Trindade, E. S.; Franco, C. R. C.; Torquato, R. J. S.; Veiga, S. S.; Valente, A. P.; Mourão, P. A. S.; Leite, E. L.; Nader, H. B.; Dietrich, C. P.; J. Biol. Chem. 2005, 280, 41278.

94. Dias, P. F.; Siqueira Jr., J. M.; Vendruscolo, L. F.; Neiva, T. J.; Gagliardi, A. R.; Maraschin, M.; Ribeiro-do-Valle, R. M.; Cancer Chemother. Pharmacol. 2005, 56, 436.

95. Noseda, M. D.; Tulio, S.; Duarte, M. E. R.; J. Appl. Phycol. 1999, 11, 35 .

96. Torres, M. R.; Sousa, A. P. A.; Silva Filho, E. A. T.; Melo, D. F.; Feitosa, J. P. A.; de Paula, R. C. M.; Lima, M. G. S.; Carbohydr. Res. 2007, 342, 2067.

97. de Sousa, A. P. A.; Torres, M. R.; Pessoa, C.; de Moraes, M. O.; Rocha Filho, F. D.; Alves, A. P. N. N.; Lotufo, L. V. C.; Carbohydr. Polym. 2007, 69, 7 .

98. Duarte, M. E. R.; Gorin, P. A. S.; Duarte, J. H.; Phytochemistry 1991, 30, 1707.

99. Farias, E. H. C.; Pomin, V. H.; Valente, A.-P.; Nader, H. B.; Rocha, H. A. O.; Mourão, P. A. S.; Glycobiology 2008, 18, 250. 
100. Pengzhan, Y.; Quanbin, Z.; Ning, L.; Zuhong, X.; Yanmei, W.; Zhi'en, L.; J. Appl. Phycol. 2003, 15, 21.

101. Leiro, J. M.; Castro, R.; Arranz, J. A.; Lamas, J.; Int. Immunopharmacol. 2007, 7, 879 .

102. Zhang, H.-J.; Mao, W.-J.; Fang, F.; Li, H.-Y.; Sun, H.-H.; Chen, Y.; Qi X.-H.; Carbohydr. Polym, 2008, 71, 428.

103. Cassolato, J. E. F.; Noseda, M. D.; Pujol, C. A.; Damonte, E. B.; Pellizzari, F. M.; Duarte, M. E. R.; Carbohydr. Res. 2008, 343, 3085.

104. de Paula, R. C. M.; Rodrigues, J. F.; Carbohydr. Polym. 1995, 26, 177.

105. de Paula, R. C. M.; Heatley, F., Budd, P.; Polym. Int. 1998, 45, 27.

106. Menestrina, J. M.; Iacomini, M.; Jones, C.; Gorin, P. A. J.; Phytochemistry 1998, 47, 715.

107. de Paula, R. C. M.; Budd, P., Rodrigues, J. F.; Polym. Int. 1997, 44 55.

108. Oliveira, J. D.; Silva, D. A.; de Paula, R. C. M.; Feitosa, J. P. A.; Paula H. C. B.; Int. J. Biol. Macromol. 2001, 29, 35.

109. de Paula, R. C. M.; Santana, S. A.; Rodrigues, J. F.; Carbohydr. Polym. 2001, 44, 33 .

110. Teixeira, D. M. A.; Braga, R. C.; Horta, A. C. G.; Moreira, R. A.; de Brito, A. C. F.; Maciel, J. S.; Feitosa, J. P. A.; de Paula, R. C. M.; Carbohydr. Polym. 2007, 70, 369.

111. de Brito, A. C. F.; Silva, D. A.; de Paula, R. C. M.; Feitosa, J. P. A.; Polym. Int. 2004, 53, 1025.

112. de Brito, A. C. F.; Sierakowski, M. R.; Reicher, F.; Feitosa, J. P. A.; de Paula, R. C. M.; Food Hydrocolloids 2005, 19, 861.

113. Silva D. A.; de Paula R. C. M.; Feitosa J. P. A.; de Brito A. C. F.; Maciel J. S.; Paula, H. C. B.; Carbohydr. Polym. 2004, 58, 163.

114. Oliveira, M. A.; Silva, D. A.; Uchoa, D. E. A.; Maciel, J. S.; Feitosa, J. P. A.; Paula, H. C. B.; de Paula, R. C. M.; J. Appl. Polym. Sci. 2007, 103, 2985.

115. Cunha, P. L. R.; Maciel, J. S.; Sierakowski, M. R.; de Paula, R. C. M.; Feitosa, J. P. A.; J. Braz. Chem. Soc. 2007, 18, 85

116. Silva, D. A.; de Paula, R. C. M.; Feitosa, J. P. A.; Eur. Polym. J. 2007, 43, 2620.

117. www.ibge.gov.br/estadosat/ em lavouras permanentes, acessada em Março 2008.

118. Bandeira, C. T.; Relatório Técnico da Empresa Brasileira de Pesquisa Agropecuária- EMBRAPA-CNPCA, 1991, 6, 1 .

119. Oliveira, M. A.; Ciarlini, P. C.; Feitosa, J. P. A.; de Paula, R. C. M.; Paula, H. C. B.; Mater. Sci. Eng. C 2009, 29, 448.

120. Rodrigues, R. A. F.; Grosso, C. R. F.; J. Microencapsulation 2008, 25, 13.

121. Mothé, C. G.; Produção de goma do cajueiro, PI 0004114-9, depositada em 12/09/2000

122. Mothé, C. G.; Correia, D. Z.; Analytica 2002, 2, 59.

123. Mothé, C. G.; Ver. Nac. Carn. 1998, 253, 20.

124. Torquato, D. S.; Ferreira, M. L.; Sá, G. C.; Brito, E. S.; Pinto, G. A. S.; World J. Microbiol. Biotechnol. 2004, 20, 505.

125. Florêncio, A. P. S.; Melo, J. H. L.; Mota, C. R. F. C.; Melo Junior, M R.; Araújo, R. V. S.; Rev. Eletr. Farm. 2007, 4, 61.

126. Schirato, G. V.; Monteiro, F. M. F.; Silva, F. O.; Lima Filho, J. L.; Leão, A. M. A. C.; Porto, A. L. F.; Ciênc. Rur. 2006, 36, 149

127. Magalhães Jr, G. A.; Santos, C. M. W.; Silva, D. A.; Maciel, J. S.; Feitosa, J. P. A.; Paula, H. C. B.; de Paula, R. C. M.; Carbohydr. Polym. 2009, doi: 10.1016/j.carbpol.2008.12.037.

128. Maciel, J. S.; Paula, R. C. M.; Paula, H. C. B.; Miranda, M. A.; Sassaki, J. M.; J. Appl. Polym. Sci. 2006, 99, 326.

129. Gonçalves, J. L. S.; Lopes, R. C.; Oliveira, D. B., Costa, S. S.; Miranda, M. M. F. S.; Romanos, M. T. V.; Santos, N. S. O.; Wigg, M. D.; J. Ethnopharmacol. 2005, 99, 403.

130. Ribeiro, R. C. C.; Correia, J. C. G.; Monte, M. B. M.; Seidl, P. R.; Mothé, C. G.; Lima, C. A.; Mater. Eng. 2003, 16, 873.
131. Guilherme, M. R.; Reis, A. V.; Takahashi, S. H.; Rubira, A. F.; Feitosa, J. P. A.; Muniz, E. C.; Carbohydr. Polym. 2005, 61, 464.

132. Guilherme, M. R.; Rubira, A. F.; Feitosa, J. P. A.; Muniz, E. C.; Patente depositada no INPI em 29/09/2004, PI 0404265-4.

133. Paula, H. C. M.; de Paula, R. C. M.; Feitosa, J. P. A. Em Brazilian Network on Green Chemistry: Awareness, responsibility and action 1; Carioca, J. O. B., org., $1^{\text {a }}$ ed., Ed. UFC: Fortaleza, 2008, p. 373-395.

134. Silva, E. E.; Tese de Doutorado, Universidade Federal de Minas Gerais, Brasil, 2007

135. Silva, D. A.; Feitosa, J. P. A.; Paula, H. C. B.; de Paula, R. C. M.; Mater. Sci. Eng. C 2009, 29, 437.

136. Maciel, J. S.; Kosaka, P. M.; Paula, R. C. M.; Feitosa, J. P. A.; Petri D. S. F.; Carbohydr. Polym. 2007, 69, 522.

137. Zierer, M. S.; Mourão, P. A. S.; Carbohydr. Res. 2000, 328, 209.

138. Guerardel, Y.; Czeszak, X.; Sumanovski, L. T.; Karamanos, Y.; Popescu, O.; Strecker, G.; Misevic, G. N.; J. Biol. Chem. 2004, 279, 15591.

139. Cimino, P.; Bifulco, G.; Casapullo, A.; Bruno, I.; Gomez-Paloma, L.; Riccio, R.; Carbohydr. Res. 2001, 334, 39.

140. Ehrlich, H.; Maldonado, M.; Spindler, K.-D., Eckert, C.; Hanke, T.; Born, R.; Goebel, K.; Simon, P.; Heinemann, S.; Worch, H.; J. Exp. Zool. 2007, 308, 347.

141. Ehrlich, H.; Krautter, M.; Hanke, T.; Simon, P.; Knieb, C.; Heinemann, S.; Worch, H.; J. Exp. Zool. 2007, 308, 373.

142. Medeiros, G. F.; Mendes, A.; Castro, R. A. B.; Baú, E. C.; Nader, H. B.; Dietrich, C. P.; Biochim. Biophys. Acta 2000, 1475, 287.

143. Dietrich, C. P.; Paiva, J. F.; Castro, R. A. B.; Chavante, S. F.; Jeske, W.; Fareed, J.; Gorin, P. A. J.; Mendes, A.; Nader, H. B.; Biochim. Biophys. Acta 1999, 1428, 273.

144. Carbonero, E. R.; Montai, A. V.; Mellinger, C. G.; Eliasaro, S.; Sassaki, G. L.; Gorin, P. A. J.; Iacomini, M.; Phytochemistry 2005, 66, 929.

145. Carbonero, E. R.; Smiderle, F. R.; Gracher, A. H. P.; Mellinger, C. G.; Ahti, T.; Gorin, P. A. J.; Iacomini, M.; Carbohydr. Polym. 2006, 63, 13.

146. Santos-Neves, J. C.; Pereira, M. I.; Carbonero, E. R.; Gracher, A. H. P.; Alquini, G.; Gorin, P. A. J.; Sassaki, G. L.; Iacomini, M.; Carbohydr. Polym. 2008, 73, 309.

147. Smiderle, F. R.; Carbonero, E. R.; Sassaki, G. L.; Gorin, P. A. J.; Iacomini, M.; Food Chem. 2008, 108, 329.

148. Kaneno, R.; Fontanari, L. M.; Santos, S. A.; Di Stasi, L. C.; Rodrigo Filho, E.; Eira, A. F.; Food Chem. Toxicol. 2004, 42, 909.

149. Gonzaga, M. L. C.; Ricardo, N. M. P. S.; Heatley, F.; Soares, S. A.; Carbohydr. Polym. 2005, 60, 43.

150. Guterrez, Z. R.; Mantovani, A. F. E.; Ribeiro, L. R.; Jordão, B. Q.; Toxicol. in Vitro 2004, 18, 301.

151. Dietrich, C. P.; Paiva, J. F.; Moraes, C. T.; Takahashi, H. K.; Porcionatto, M. A.; Nader, H. B.; Biochim. Biophys. Acta 1985, 843, 1

152. Vieira, R. P.; Pedrosa, C.; Mourão, P. A. S.; Biochemistry 1993, 32, 2254.

153. Vieira, R. P.; Mourão, P. A. S.; J. Biol. Chem. 1988, 263, 18176.

154. Pavão, M. S. G.; Aiello, K. R. M.; Werneck, C. C.; Silva, L. C. F.; Valente, A.-P.; Mulloy, B.; Colwell, N. S.; Tollefsen, D. M.; Mourão, P. A. S.; J. Biol. Chem. 1998, 273, 27848.

155. Cardilo-Reis, L.; Cavalcante, M. C. M.; Silveira, C. B. M.; Pavão, M. S. G.; Braz. J. Med. Biol. Res. 2006, 39, 1409

156. Stuelp-Campelo, P. M.; Oliveira, M. B. M.; Leão, A. M. A. C.; Carbonero, E. R.; Gorin, P. A. J.; Iacomini, M.; Int. Immunopharmacol. 2002, 2, 691 .

157. Kurozawa, L. E.; El-Aouar, A. A.; Murr, F. E. X.; Ciênc. Tecnol. Aliment. 2005, 25, 828 .

158. Campana-Filho, S. P.; Britto, D.; Abreu, F. R.; Cardoso, M. B.; Battisti, M. V.; Sim, P. C.; Goy, R. C.; Signini, R.; Lavall, R. L.; Quim. Nova 2007, 30, 644 .

159. Lavall, R. L.; Assis, O. B. G.; Campana-Filho, S. P.; Biores. Technol. 2007, 98, 2465. 
160. Laus, R.; Geremias, R.; Vasconcelos, H. L.; Laranjeira, M. C. M.; Fávere, V. T.; J. Hazard. Mater. 2007, 149, 471.

161. Vasconcelos, H. L.; Fávere, V. T.; Gonçalves, N. S.; Laranjeira, M. C. M.; React. Func. Polym. 2007, 67, 1052.

162. Paulino, A. T.; Guilherme, M. R,; Reis, A. V.; Tambourgi, E. B.; Nozakiand, J.; Muniz, E. C.; J. Hazard. Mater. 2007, 147, 139.

163. Prado, A. G. S.; Torres, J. D.; Faria, E. A.; Dias, S. C. L.; J. Colloid. Interface Sci. 2004, 277, 43.

164. Borato, C. E.; Leite, F. L.; Mattoso, L. H. C.; Goy, R. C.; Campana Filho, S. P.; Vasconcelos, C. L.; Trindade Neto, C. G.; Pereira, R. M.; Fonseca, J. L. C.; Oliveira Jr, O. N.; IEEE Trans. Dielectr. Electr. Insul. 2006, 13, 1101.

165. Oliveira, I. R.W.; Fernandes, S. C.; Vieira, I. C.; J. Pharm. Biomed. Anal. 2006, 41, 366.

166. Maciel, J. S.; Silva, D. A.; Paula, H. C. B.; de Paula, R. C. M.; Eur. Polym. J. 2005, 41, 2726.

167. Shi, J.; Alves, N. M.; Mano, J. F.; J. Biomed. Mater. Res. Part B 2008, $84 B, 595$.
168. Paula, H. C. B.; de Paula, R. C. M.; Bezerra, S. K. F.; J. Appl. Polym. Sci. 2006, 102, 395.

169. Sarmento, B.; Ribeiro, A.; Veiga, F.; Ferreira, D.; Neufeld, R.; Biomacromolecules 2007, 8, 3054.

170. Sarmento, B.; Ribeiro, A.; Veiga, F.; Sampaio, P.; Neufeld, R.; Ferreira, D.; Pharm. Res. 2007, 24, 2198.

171. Reis, C.; Ribeiro, A. J.; Veiga, F.; Neufeld, R. J.; Damge, C.; Drug Delivery 2008, 15, 127.

172. Pinheiro, E. R.; Silva, I. M. D. A.; Gonzaga, L. V.; Amante, E. R.; Teófilo, R.F.; Ferreira, M. M. C.; Amboni, R. D. M. C.; Bioresour. Technol. 2008, 99, 5561.

173. Braga, M. R.; Carpita, N. C.; Dietrich, S. M. C.; Figueiredo-Ribeiro, R. C. L.; Braz. J. Plant Physiol. 2006, 18, 325.

174. Ferro, A. F. P.; Bonacelli, M. B. M.; Assad, A. L. D.; Gestão Prod. 2006, 13, 489.

175. Ferraz, J. C.; Valor Econômico, 2009, 6 de Janeiro. 